\title{
К ВОПРОСУ РАЗВИТИЯ ЧИТАТЕЛЬСКОЙ ГРАМОТНОСТИ УЧАЩИХСЯ
}

\section{TO THE QUESTION OF DEVELOPING THE READING LITERACY OF STUDENTS}

B. Karimova

N. Zhetpeisova

Sh. Baimahanova

Summary: The article describes the role and features of context-oriented tasks for the development of functional literacy of students. According to the experts of the international PISA study, Kazakhstani students experience difficulties in solving contextual problems: a small part of the students were able to solve mathematical problems included in usual context, and could not give answers in context-oriented tasks.

Context is a real life situation, a specific area of life. Using the example of the PISA task, some recommendations are given for the development of students' reading literacy as part of a general understanding of the text, taking into account the aspects of analysis, combination and interpretation.

Keywords: context, context-oriented task, reader literacy, functional orientation, productive tasks, reflection, assessment.
Каримова Бейбиткуль Сарсемхановна

к.филол.н., асс.професссор, Кызылординский государственный университет им. Коркыт Ата, Казахстан, г. Кызылорда karimovab72@mail.ru

Жетпеисова Нурымкуль Оразовна к.п.н., асс.профессор, Кызылординский государственный университет им. Коркыт Ата, Казахстан, г. Кызылорда

nur.oras@mail.ru

Баймаханова Шолпан Усеновна

Кызылординский государственный университет им. Коркыт Ата, Казахстан, г. Кызылорда y.sholpan@mail.ru

Аннотация: В статье описываются роль и особенности контекстно-ориентированных заданий для развития функциональной грамотности учащихся. Как установили эксперты международного исследования PISA казахстанские обучающиеся испытывают трудности при решении контекстных задач: незначительная часть обучающихся смогли решить математические задачи, включенные в привычный контекст, и не смогли дать ответы в контекстноориентированных заданиях.

Контекст - это реальная жизненная ситуация, определенная сфера жизни. На примере задания PISA даются некоторые рекомендации по развитию у учащихся читательской грамотности в рамках развития общего понимания текста с учетом аспектов анализа, комбинирования и интерпретации.

Ключевые слова: контекст, контекстно-ориентированное задание, читательская грамотность, функциональная направленность, продуктивные задания, рефлексия, оценка.

\section{Ввецение}

B 2019 году организаторы международного исследования PISA-2018 опубликовали первые результаты. 15-летние учащиеся школ и студенты колледжей из Казахстана показали наихудший результат за все годы участия в этой программе. Школьники из 79 стран и экономических зон приняли участие в данном исследовании, учащиеся - казахстанцы заняли 69 место [1, с.1].

PISA (Programme for International Student Assessment) - это программа международного исследования образовательных достижений, по-другому исследование уровня функциональной грамотности 15-летних обучающихся. Программа исследования была запущена в 2000 году, проводится циклично каждые три года, в каждом цикле определяется приоритетное направление по читательской $(2000,2009,2018)$, математической $(2003,2012)$ и естественнонаучной грамотности $(2006,2015)$.

Республика Казахстан четырежды принимала уча- стие в международном исследовании. С 2009 года государство демонстрировало рост, а в 2018 году показало снижение. В 2009 году из 69 стран Казахстан занял в общем рейтинге 59 место.

В последующие годы результаты были немного лучше, но исследование 2018 года выявило отставание от собственных результатов прошлых лет с разницей: по математике - 37 баллов, по естествознанию - 59 и по читательской грамотности - 40 баллов.

Большая часть казахстанских школьников достигли 2-го уровня и ниже. Это говорит о том, что 15-летние учащиеся не могут анализировать и понимать прочтенный текст. Выяснилось, что большинство тестируемых школьников не пользуется минимальным объемом знаний по математике и естествознанию, и только очень малая часть их достигли наивысших 5-6 уровней по трем направлениям грамотности.

Ситуационные примеры из жизни обучающихся яв- 
ляются существенной основой для усвоения предлагаемого содержания обучения. При решении продуктивных или контекстных задач обучающиеся затрудняются в понимании проблемы, в разграничении основной и неосновной информации, в процессе идентификации реальной ситуации с учебной темой [2, с.34].

Цель заданий по оценке читательской грамотности: ответить на несколько вопросов к одному или к ряду текстов. Тестируемому даются контекст и цель, которая позволяет определить способы поиска, понимания и интеграции информации. Все задания основаны на реальных ситуациях.

После проведенного анализа результатов исследования казахстанским участникам образовательного процесса были даны краткие рекомендации, среди которых мы, как преподаватели, обратили внимание на следующую рекомендацию: необходимо все задания, которые были в PISA, внедрять в учебные программы школ. Разработать подобные задачи и материалы для программы обновленного содержания образования.

Способность обучающихся применять полученные знания и умения в разных контекстах повседневной реальной жизни рассматривается как основная цель обучения. Задания на развитие читательской грамотности, составленные по примерам заданий PISA, могут применяться в качестве дидактического материала и при обучении математике и естественным наукам. Следующий пример задания на развитие читательской грамотности взят нами из исследований PISA прошлых лет. [3]

\section{Пример задания PISA}

\section{Безопасность сотового телефона.}

Ключевое утверждение: Со времени появления сотовых телефонов периодически появляются разные, порой противоречивые сообщения, что сотовые телефоны представляют риски для здоровья.

Ключевое утверждение: Чтобы изучить воздействие сотового телесона на организм человека, в научные исследования инвестированы миллионы евро.

Таблица 1.

Опасны ли сотовые телефоны?

\begin{tabular}{|c|c|}
\hline Да & Нет \\
\hline $\begin{array}{l}\text { 1.Радиоволны. излучаемые со- } \\
\text { товыми телефонами, могут на- } \\
\text { гревать ткани тела и вызвать их } \\
\text { повреждение. }\end{array}$ & $\begin{array}{l}\text { Радиоволны недостаточно сильны, } \\
\text { чтобы нагревать и повреждать тка- } \\
\text { ни тела. }\end{array}$ \\
\hline
\end{tabular}

\section{Да}

2. Излучаемые телефонами магнитные волны могут воздействовать на функции клеток тела.

3. Люди, которые очень долго ведут телефонные разговоры, жалуются на бессилие, головные боли и понижение способности концентрации внимания.

4. У пользователей сотовых телефонов в 2,5 раза повышен риск возникновения опухоли головного мозга.

5. Международный центр исследования раковых заболеваний установил, что существует связь между раком у детей и линией электропередачи.

6. Волны высокой частоты, аналогичные волнам сотового телефона изменяют факторы наследственности у земляных червей.

Ключевое утверждение: Если учесть большое и всё растущее количество пользователей сотовыми телефонами и их отрицательное влияние на здоровье человека, то это может отразиться на здоровье всего народа.

Ключевое утверждение: B 2000 году «Cтюарт Peпорт» (британский отчет) отметил, что сотовые телефоны не вызывают проблемы со здоровьем, но призвало в первую очередь молодежь к осторожности, пока идет дальнейшее исследование. Отчет 2004 года подтвердил это.

\section{Вопрос: Безопасность сотового телефона.}

\section{Какова чель ключевых фрраз?}

А.Указать на опасность пользования сотовыми телесонами.

В. Обратить внимание на актуальность дискуссий о безопасности сотовых телефонов.

C. Предупредить, какие меры предосторожности должны предпринять пользователи сотовых телефонов.

D. Указать на то, что никаких проблем со здоровьем, которые вызваны сотовыми телесонами, не обнаружеHO.

\section{Вопрос: Безопасность сотового телефона.}

Информачия: «Трудно доказать, что одно явление непременно было вызвано другим». 
Как взаимосвязаны эта информачия и аргументы Да/Нет пункта 4 таблицы «Опасны ли сотовые телефоны?»

A. Cоответствует аргументу Да, но не доказывает ezo.

В. Поддерживает аргумент Да.

C. Cоответствует аргументу Hem, но не доказываem ero.

D. Доказывает, что аргумент Hem неверный.

\section{Bопрос: Безопасность сотового телефона.}

Посмотри пункт 3 таблицы в графе НЕT. Что могло бы быть «другим фактором» в этой взаимосвязи. Обоснуй свой ответ.

Таблица 2.

Если ты пользуешься сотовым телефоном, ...

\begin{tabular}{|c|c|}
\hline делай так. & не делай так. \\
\hline Говори по телефону кратко & $\begin{array}{l}\text { Не пользуйся телефоном, если } \\
\text { связь слабая, так как он требует } \\
\text { больше энергии, чтобы связаться с } \\
\text { сетью. Это вызывает более сильное } \\
\text { излучение. }\end{array}$ \\
\hline $\begin{array}{l}\text { Не подноси телефон близко к телу, } \\
\text { пока он в режиме ожидания. }\end{array}$ & $\begin{array}{l}\text { Не покупай телефон с высоким } \\
\text { SAR-Wert (Удельным коэффициен- } \\
\text { том поглощения электромагнит- } \\
\text { ной энергии. Данным показателем, } \\
\text { в частности, измеряют величину } \\
\text { вредного воздействия мобильных } \\
\text { телефонов на человека). } \\
\text { Это означает, что от такого теле- } \\
\text { фона идет большое излучение. }\end{array}$ \\
\hline $\begin{array}{l}\text { Покупай телефон с качественным } \\
\text { приемом связи. Они мощнее и } \\
\text { излучение от них меньше. }\end{array}$ & $\begin{array}{l}\text { Не покупай защитные аксессуары, } \\
\text { если они не протестированы неза- } \\
\text { висимой стороной. }\end{array}$ \\
\hline
\end{tabular}

\section{Boпрос: Безопасность сотового телефона}

Посмотри таблицу «Если ты пользуешься сотовым телефоном». На каком из этих высказываний основана таблица?

А. Нет никакой опасности при пользовании сотовыми телефонами.

В. При пользовании сотовыми телефонами имеются доказанные риски.

C. Использование сотовых телефонов может быть опасным или не опасным. В любом случае разумно предпринять меры предосторожности.

D. Использование сотовых телефонов может быть опасным или неопасным, Но ими нельзя пользоваться, пока не установили степень их безопасностьи.

E. Указание Делай так предназначается для тех, кто серьезно воспринимает эту угрозу. Указание Не делай так предназначено для всех других.
Задание составлено в рамках развития общего понимания текста с учетом аспекта комбинирования и интерпретации. Целью является определение темы конкретной повторяющейся информации, в данном случае состоящей из четырех ключевых утверждений, расположенных перед двумя основными текстами, представленными в формате таблиц. Важным элементом учебной среды, основанной на контексте, является активное обучение: от учащихся требуется чувство сопричастности к предмету и ответственность за собственное обучение. Комбинация самостоятельного обучения и использования контекстов согласуется с таким подходом, что люди конструируют свои собственные значения из своего опыта, а не получают знания из других источников $[4$, c.5]

Первый текст - «Опасны ли сотовые телефоны?» представляет собой таблицу из двух противоположных мнений-аргументов «Да/Нет» по безопасности сотовых телефонов.

Сначала учащийся работает с одним текстом, отвечает на вопросы по его содержанию.

Затем учащийся читает второй текст и отвечает на ряд вопросов, касающихся содержания второго текста. И только после этого учащемуся необходимо ответить на вопросы, которые требуют обобщения информации из ключевых утверждений и обоих текстов.

Это задание требует от учащегося определить связь между общим утверждением, которого нет в тексте, и некоторыми утверждениями в таблице. На основе этого внешнего ориентира проверяются аспекты рефлексии и оценки. Это самая сложная работа в задании по безопасности сотового телефона; по степени сложности он находится на границе между уровнем 4 и уровнем 5.

Учитывая все трудности, связанные с этой задачей, в отчетах значится, что чуть более трети студентов в странах ОЭСР сделали это правильно [3].

К вопросу 2. Посмотри на пункт 3 в столбие «Нет» 8 табличе. Что может быть одним из «других факторов» в этом контексте? Обоснуйте свой ответ.

В этом задании ученики также должны размышлять над содержанием текста и оценивать его; речь идет об умении устанавливать связь со знаниями вне текста. Они должны привести пример из собственного опыта других факторов современной жизни, не связанных с мобильным телефоном, которые могут быть вызваны «усталостью, головными болями и снижением концентрации внимания».

К вопросу «Посмотри на табличу «Если ты пользу- 
ешься мобильным телесоном ...». На каком из следующих предположений основана таблица?

Положительная оценка при ответе С. Сотовые телефоны могут быть опасны или не опасны, но имеет смысл принять меры предосторожности.

В этом задании ученикам нужно просмотреть вторую таблицу и понять основную идею, что при отсутствии явных доказательств опасности, исходящей от сотовых телефонов, следует проявлять осторожность.

Вариант C - лучший ответ, поскольку он согласуется как с основным сообщением, так и с отдельными инструкциями в столбцах «Делай так» и «Не делай так».

В анализах исследования PISA отмечено, что почти две трети учеников выбрали правильный ответ, и данная задача стала самой лёгкой в этом довольно трудном контекстно-ориентированном задании.

Контекстно-ориентированные задания - это не только комбинирование всей представленной информации, задания могут содержать больше информации, чем нужно для решения, или информации может быть недостаточно. Представление большего или меньшего количества информации для решения подобных заданий нужно рассматривать как стимулирование обучающегося для поиска нужного решения, а не простого выпол- нения действия. Поэтому учащимся нужно предложить различные типы информации, например: соответствующие, недостаточные, излишние. Таким образом, они научатся отбирать нужную, игнорировать или, наоборот, дополнять информацию.[5]

\section{Зак^ючение}

Наличие контекстно-ориентированных заданий в школьных учебниках способствует формированию и развитию функциональной грамотности обучающихся, их умению применять полученные знания и умения для решения жизненных задач.

Функциональную направленность учебника/учебных материалов можно определить по тому факту, если в учебнике приводятся примеры реальных ситуаций из повседневной жизни обучающихся и в равных пропорциях представлены разные ситуации из жизни на селе или из жизни в городе.

Анализ показал, что в содержании казахстанских школьных учебников отсутствуют задания, составленные по аналогии с заданиями PISA и формирующие читательскую грамотность школьников. А именно заданий, для решения которых от ученика требуется не только осмысление их формы, но также интерпретация текстов, отклик на него, рефлексия и оценка.

\section{ЛИТЕРАТУРА}

1. PISA-2018: казахстанские школьники впервые за 10 лет ...https://informburo.kz > stati > pisa-2018-kazahstanskie-... c.1.

2. http://documents1.worldbank.org/curated/es/230321468263647366/pdf

3. https://www.n-tv.de/politik/Lesekompetenz-Handysicherheit-rticle2090581.html

4. Marion Haugwitz. Kontextorientiertes Lernen und Cocept Mapping im Fach Biologie. Eine experimentelle Untersuchung. Inaugural Dissertation zur Erlangung des Doktorgrades. 2009.

5. Каримова Б.С., Жетпеисова Н.О. Фундаментальная и функциональная составляющие школьного учебника: анализ и рекомендации. Вестник КазНПу им. Абая. Серия «Педагогические науки» №3(59), 2018 г. сс.226-233

( К Каримова Бейбиткуль Сарсемхановна (karimovab72@mail.ru),Жетпеисова Нурымкуль Оразовна (nur.oras@mail.ru), Баймаханова Шолпан Усеновна (y.sholpan@mail.ru).

Журнал «Современная наука: актуальные проблемы теории и практики» 